\title{
A METHOD FOR ESTIMATING THE ORIGIN TIME OF AN ENSUING MAINSHOCK BY OBSERVATIONS OF PRESHOCK CRUSTAL SEISMIC DEFORMATION
}

\author{
B.C.PAPAZACHOS ${ }^{1}$, G.F.KARAKAISIS ${ }^{1}$, C.B.PAPAZACHOS ${ }^{1}$, E.M.SCORDILIS ${ }^{1}$ AND A.S.SAVVAIDIS ${ }^{1}$
}

\begin{abstract}
Observations on accelerating crustal deformation due to the generation of intermediate magnitude preshocks in the Aegean area are used to propose a method for prediction of the origin time of an ensuing mainshock. The method is based on a precursory seismic excitation that occurs in the preshock region at a time correlated to the origin time of the oncoming mainshock. The uncertainty in this prediction is of the order of \pm 1.5 years with relatively high confidence ( $90 \%)$.
\end{abstract}

KEYWORDS: Accelerating seismic deformation, earthquake prediction, precursory excitation, Aegean area

\section{INTRODUCTION}

Observations on accelerating seismicity before large earthquakes have started several decades ago and continued with increasing frequency during the last two decades (Gutenberg and Richter, 1954; Tocher, 1959; Mogi, 1969; Ellsworth et al., 1981; Raleigh et al., 1982; Sykes and Jaume, 1990; Knopoff et al., 1996). Attempts to give a physical interpretation to this phenomenon led to the scientific hypothesis that the process of generation of accelerating preshock seismicity is a critical phenomenon and the mainshock is a critical point (Sornette and Sornette, 1990; Andersen et al., 1997). This accelerating seismicity is due to the generation of intermediate magnitude shocks (preshocks) and for this reason, measures of crustal deformation (Benioff strain, seismic energy, seismic moment) have been used. Thus, Bufe and Varnes (1993) used the cumulative Benioff strain, $\mathrm{S}(\mathrm{t})$, as a measure of preshock seismicity at time, $\mathrm{t}$, defined as:

$$
S(t)=\sum_{i=1}^{n(t)} E_{i}(t)^{1 / 2}
$$

where $E_{i}$ is the seismic energy of the ith preshock and $n(t)$ is the number of events at time t. To fit the time variation of the cumulative Benioff strain they proposed a relation of the form:

$$
S(t)=A+B\left(t_{c}-t\right)^{m}
$$

where $t_{c}$ is the origin time of the mainshock and $A, B, m$ are parameters which can be calculated by the available data. Bowman et al. (1998) applied an algorithm to identify circular regions approaching criticality along the San Andreas fault system since 1950 by minimizing a curvature parameter, C, which quantifies the degree of acceleration of the Benioff strain. This parameter was defined as a ratio of the root mean square error of the power law fit (relation 2) to the corresponding linear fit error.

Some observations on accelerating seismicity before strong earthquakes in Greece have been made during the last two decades (Papadopoulos, 1986; Karakaisis et al., 1991; Tzannis et al., 2000). Very recently a systematic work on the accelerating seismic crustal deformation (Benioff strain) in the Aegean area has started (Papazachos and Papazachos, 2000a,b). This work has led to the determination of additional properties of the critical earthquake model and to the formation of an algorithm for identification of elliptical critical regions where accelerating seismic deformation takes place. Evidence has been also come out from this work that accelerating seismic deformation can be useful in intermediate term earthquake prediction. In the present work data of such deformation in the Aegean area $\left(34^{0} \mathrm{~N}-43^{\circ} \mathrm{N}, 19^{\circ} \mathrm{E}-30^{\circ} \mathrm{E}\right)$ are used to further understand this physical process and to show that a recognizable change (seismic excitation) in the behavior of the time variation of the cumulative Benioff strain can be considered as a precursory phenomenon which can be used to estimate the origin time of an ensuing mainshock that follows accelerating deformation.

1. Geophysical Laboratory, Aristotle University, GR-54006, Thessaloniki, GREECE 


\section{BACKGROUND AND DATA}

Papazachos and Papazachos (2000a,b) determined several relations for the parameters of the critical earthquake model. Thus, the values of the curvature parameter, $\mathrm{C}$, and of the parameter $\mathrm{m}$ of relation (2) must be both smaller than 0.7 , that is,

$$
C<0.7, m<0.7
$$

The radius, $\mathrm{R}$ (in $\mathrm{km}$ ), of the circle with area equal to the elliptical preshock region is given by the relation:

$$
\log R=0.41 M-0.64
$$

where $M$ is the moment magnitude of the main shock, while the duration, $t_{p}$ (in years), of a preshock sequence is given by the relation:

$$
\log t_{p}=5.81-0.75 \log s_{r}
$$

where $s_{r}$ is the long term rate of the Benioff strain (in Joule $e^{1 / 2}$ per year and per $10,000 \mathrm{~km}^{2}$ ) in the preshock region. The following relations hold for the parameters A and B of formula (2):

$$
\begin{aligned}
& A=S_{r} t_{p} \\
& \log B=0.64 M+3.27
\end{aligned}
$$

where $\mathrm{S}_{\mathrm{r}}$ (in Joule ${ }^{1 / 2} / \mathrm{yr}$ ) is the rate of the Benioff strain in the whole preshock region. The magnitude of the mainshock is related to the mean magnitude of the three largest preshocks, $\mathbf{M}_{13}$, by the relation:

$$
M=0.85 M_{13}+1.52
$$

Relations $(2,3,4,5,6,7,8)$ form the background for the method proposed in the present paper. Equations (4) and (5) are the main scaling (fractal) equations defining the space and time-scale of the accelerated deformation phenomenon. Both equations, as well as the model equation (2), are supported by theoretical considerations, e.g. equation (5) simply implies that larger average deformation (i.e. seismicity) rates will sooner lead to criticality. On the other hand, relation (3) defining the detection limits of the accelerated deformation process, as well as equations (6), (7) and (8) are based on more or less empirical observations describing regularities and patterns of the accelerated deformation behavior.

The data used for this purpose have been taken from a catalog of earthquakes that occurred in the Aegean area (Papazachos et al., 2000). The earthquakes for which data are used in this paper form the following three complete data sets: $1911-1949$ with $\mathrm{M}^{3} 5.0,1950-1964$ with $\mathrm{M}^{3} 4.5,1965-2000$ with $\mathbf{M}^{3} 4.3$. The standard errors in the epicenters are less than $25 \mathrm{~km}$, while all magnitudes are equivalent moment magnitudes with standard errors of the order of 0.3 . The formula:

$$
\log E=1.5 M+4.7
$$

has been used to calculate the seismic energy (in Joule) from the moment magnitude (Papazachos and Papazachos 2000a) and then the Benioff strain is calculated by relation (1).

\section{IDENTIFICATION TIME}

Accelerating seismic deformation with the properties defined by relations $(2,3,4,5,6,7,8)$ cannot be identified up to a certain time, $\mathrm{t}_{\mathrm{i}}$, before the expected main shock which can be called "identification time". We calculated the identification time for preshock sequences of 54 strong $\left(\mathrm{M}^{3} 6.0\right)$ shallow mainshocks occurred in the Aegean area. The time-lapse between the identification time and the origin time of the corresponding mainshocks vary between 1.2 years and 8.3 years with a mean equal to 3.7 years and a standard deviation equal to 1.6 years. It was observed that the logarithm of this difference is a linear function of the logarithm of the rate, $\mathrm{s}_{\mathrm{r}}$, of the Benioff strain in the corresponding preshock region. Least squares give a slope equal to 0.8 for this relation, which is almost identical to the slope of the corresponding relation for the whole duration, $t_{p}$, of the sequence (relation 5). Thus, adopting a slope equal to 0.75 for the present case the following relation results:

$$
\log \left(t_{c}-t_{i}\right)=5.04-0.75 \log s_{r}, \sigma=0.15
$$

From this and equation (5) we find that:

$$
t_{c}-t_{i}=(0.17 \pm 0.06) t_{p}
$$

That is, the difference between the identification time and the origin time of the mainshock is about seventeen per cent of the whole duration of the preshock sequence. 
Relations $(10,11)$ can be used to estimate the origin time of an oncoming mainshock. To do this, however, the identification time must be known. Furthermore, the uncertainties in the calculated origin time, $t_{c}$, by these relations are rather high. For this reason other procedures must be used for a more accurate prediction of the origin time of an ensuing mainshock. Such procedure is examined in the next section.

\section{PROCEDURE FOLLOWED}

The events used for the presented procedure include all very strong mainshocks $\left(\mathrm{M}^{3} 6.5\right)$ that occurred in the Aegean area since 1940 and all strong mainshocks (6.0£M£6.4), which occurred in this area since 1970 (a total of 32 mainshocks). Information on these events is presented in Table (1). Properties of the relation $T_{i=} f\left(T_{c}\right)$ between assumed origin times, $\mathrm{T}_{c}$, of an oncoming mainshock and the corresponding calculated identification times, $T$, during the last period of its preshock sequence are used here to determine its real origin time, $t$. It must be pointed out that in the algorithm applied to identify the elliptical preshock region and make these calculations the time of observation is always considered equal to $\mathrm{T}$. That is, the real data used in the calculations concern only shocks (preshocks) which occur up to the time $T_{\text {ind }}$ and the $S(t)$ is linearly extrapolated up to the assumed origin time, $T_{c}$. Observations show that the relation $T_{i=} f\left(T_{c}\right)$ has several forms which depend on the behavior of the seismic activity in the preshock region.

The simplest form of $T_{i=} f\left(T_{c}\right)$ is that in which $T_{i}$ is almost constant, that is, $T_{i}$ does not depend on $T_{c}$ and the $T_{i}-T_{c}$ graph is a straight line almost parallel to the $T_{c}$ axis. Such behavior of this function is expected when the initiation of the last phase of the accelerated deformation period is clearly identified, whatever the possible value of $T_{c}$ which is assumed. In these cases $t_{i}$ is equal to the constant $T_{i}$ value and it can be used in relations (10, 11) to calculate $t_{c}$. Observations show, however, that such cases (with constant $T_{i}$ ) are rather rare, since only two such cases have been identified.

In several cases the $T_{i}=f\left(T_{c}\right)$ graph is formed by two parts separated by a abrupt increase (jump) of $T_{i}$ at a certain time $T_{c}=T_{p r}$ which is close to the origin time of the main shock $\left(T_{p r} \gg t\right)$. For 12 cases a single, large jump was identified. Comparison of the predicted, $t_{c}{ }^{*}$, with the observed, $t_{c}$, origin time for these cases resulted in an average difference practically equal to zero with a standard deviation of 0.88 years for the difference $t_{c}-t_{c}{ }_{c}^{*}$. This jump of $T_{i}$ can be attributed to a seismic excitation (e.g. earthquake swarm, etc.) which occurs at a certain time $T_{i}$ which corresponds to $T_{c}=T_{p r}$, that is, to an abrupt increase of the deformation rate, $s_{r}$, which leads to such increase of $T_{i}$ according to relation (10). This is strongly supported by the fact that this increase of $T_{i}$ is usually associated with changes of the other parameters, expected to be affected by seismic excitation. Such changes are the increase of the frequency of the number of preshocks, $n$, as well as the decrease of the curvature parameter, $\mathrm{C}$, parameter $\mathrm{m}$, and the difference, $\mathrm{t}_{13}$, between the mean origin time of the three largest preshocks and the origin time of the mainshock. The decrease of $\mathrm{C}$ and $\mathrm{m}$ is explained by the additional deviation from linearity of $\mathrm{S}(\mathrm{t})$ caused by the seismic excitation, while the decrease of $\mathrm{t}_{13}$ is clearly due to the occurrence of at least one of the three largest preshocks during this seismic excitation. The study of the same 12 cases showed that largest expected changes in these four quantities exhibit a very good correlation with the $\mathrm{T}_{\mathrm{pr}}$ values, both in their position, as well as their values (increase for $n$, decrease for $C, M$ and $t_{13}$ ).

In many cases (preshock sequences) the $T_{i}-T_{c}$ graph is not simple but includes more than one jumps of $T_{i}$. In these cases we have tested if the precursory seismic excitation can still be recognized using the observed changes of all five parameters mentioned above $\left(T_{i}, n, C, m, t_{13}\right)$, given that the latter four correlate very well with the $T_{i}$ change. For this reason the rate of change with time of each one of these five parameters (positive for $\mathrm{T}_{\mathrm{i}}, \mathrm{n}$ and negative for $\mathrm{C}, \mathrm{m}, \mathrm{t}_{13}$ ) were used as a measure of the seismic excitation. Considering the relative rate for each parameter (e.g. its ratio to the maximum absolute value observed during the whole period examined) a measure of the seismic excitation expressed in terms of all these five ratios $\left(r_{i}, r_{n}, r_{c}, r_{m}, r_{t}\right)$ was calculated for the complete examined period. The average of the five relative values (considering the appropriate signs for the $r_{c}, r_{m}, r_{t}$ ratios) was considered as such measure and was called Preshock Excitation Indicator (PEI). Its values vary between 0 and 1 for relative increase of the precursory seismic activity (with respect to the activity predicted by relation 2) and between 0 and -1 for relative decrease of this activity (seismic quiescence). Since it was found that the PEI( $\left.T_{i}\right)$ function takes its maximum value at $T_{c}=T_{p r}$ (for cases with clear abrupt increase of the $T_{i}-T_{c}$ curve) it can be expected that it is very helpful for defining the origin time of an oncoming mainshock, also in the cases when the $T_{i}-T_{c}$ graph includes more than one jumps of $T_{i}$. Indeed, the average PEI value was found equal to 0.48 with a standard deviation of 0.28 , clearly indicating a high, statistically significant positive change, different from zero. A change of the slope of the $T_{i}=f\left(T_{c}\right)$ graph usually occurs at $T_{c}=T_{p r}$, which might also be helpful for defining $T_{p r}$. Observations show that this precursory seismic excitation occurs at a time $T_{i}$, which is close to the identification time $t_{i}\left(T_{i-}^{\prime} t_{i}\right)$. Therefore, this technique also gives the possibility for the estimation of the 
Table 1. Information on the 32 events used in the present study. The last two columns denote the observed ( $T_{\text {obs }}$ ) and predicted $\left(T_{p r}\right)$ origin times (in yrs) for each event.

\begin{tabular}{|c|c|c|c|c|c|c|c|c|}
\hline$N$ & $T i$ & me & & Lat. & Lon. & $M_{\text {W }}$ & $T_{\text {obs }}$ & $T_{p r}$ \\
\hline 1 & 1947 & 10 & 06 & 36.96 & 21.68 & 7.0 & 1947.77 & 1948.51 \\
\hline 2 & 1948 & 02 & 09 & 35.50 & 27.20 & 7.1 & 1948.11 & 1949.11 \\
\hline 3 & 1952 & 12 & 17 & 34.40 & 24.50 & 7.0 & 1952.53 & 1952.90 \\
\hline 4 & 1953 & 03 & 18 & 40.02 & 27.53 & 7.4 & 1953.22 & 1952.46 \\
\hline 5 & 1953 & 08 & 12 & 38.10 & 20.60 & 7.2 & 1953.62 & 1954.36 \\
\hline 6 & 1954 & 04 & 30 & 39.28 & 22.29 & 7.0 & 1954.33 & 1955.08 \\
\hline 7 & 1955 & 07 & 16 & 37.55 & 27.05 & 6.9 & 1955.54 & 1956.04 \\
\hline 8 & 1956 & 07 & 09 & 36.64 & 25.96 & 7.5 & 1956.53 & 1956.02 \\
\hline 9 & 1957 & 04 & 25 & 36.50 & 28.60 & 7.2 & 1957.35 & 1956.32 \\
\hline 10 & 1960 & 05 & 26 & 40.63 & 20.65 & 6.5 & 1960.41 & 1961.65 \\
\hline 11 & 1968 & 02 & 19 & 39.50 & 25.00 & 7.1 & 1968.14 & 1966.63 \\
\hline 12 & 1970 & 03 & 28 & 39.16 & 29.42 & 7.1 & 1970.24 & 1970.99 \\
\hline 13 & 1972 & 05 & 04 & 35.10 & 23.60 & 6.5 & 1972.34 & 1971.09 \\
\hline 14 & 1975 & 03 & 27 & 40.40 & 26.10 & 6.6 & 1975.24 & 1975.48 \\
\hline 15 & 1976 & 05 & 11 & 37.40 & 20.40 & 6.5 & 1976.36 & 1977.36 \\
\hline 16 & 1978 & 06 & 20 & 40.61 & 23.27 & 6.5 & 1978.84 & 1978.84 \\
\hline 17 & 1979 & 04 & 15 & 41.97 & 19.00 & 7.1 & 1979.29 & 1978.79 \\
\hline 18 & 1980 & 07 & 09 & 39.27 & 22.83 & 6.5 & 1980.53 & 1980.77 \\
\hline 19 & 1981 & 02 & 24 & 38.07 & 23.00 & 6.7 & 1981.15 & 1981.90 \\
\hline 20 & 1981 & 12 & 19 & 39.00 & 25.26 & 7.2 & 1981.97 & 1980.47 \\
\hline 21 & 1983 & 01 & 17 & 38.10 & 20.20 & 7.0 & 1983.05 & 1981.54 \\
\hline 22 & 1983 & 07 & 05 & 40.30 & 27.20 & 6.4 & 1983.51 & 1983.51 \\
\hline 23 & 1986 & 09 & 13 & 37.05 & 22.11 & 6.0 & 1986.70 & 1986.95 \\
\hline 24 & 1988 & 10 & 16 & 37.91 & 21.06 & 6.0 & 1988.79 & 1989.79 \\
\hline 25 & 1990 & 12 & 21 & 40.92 & 22.36 & 6.0 & 1990.98 & 1990.22 \\
\hline 26 & 1992 & 04 & 30 & 35.10 & 26.60 & 6.1 & 1992.33 & 1991.08 \\
\hline 27 & 1992 & 11 & 06 & 38.16 & 27.05 & 6.2 & 1992.88 & 1993.13 \\
\hline 28 & 1994 & 09 & 01 & 41.15 & 21.20 & 6.1 & 1994.67 & 1993.16 \\
\hline 29 & 1995 & 05 & 13 & 40.16 & 21.67 & 6.6 & 1995.37 & 1994.61 \\
\hline 30 & 1995 & 06 & 15 & 38.37 & 22.15 & 6.4 & 1995.46 & 1996.20 \\
\hline 31 & 1997 & 10 & 13 & 36.45 & 22.16 & 6.4 & 1997.79 & 1996.03 \\
\hline 32 & 1997 & 11 & 18 & 37.58 & 20.57 & 6.6 & 1997.88 & 1997.13 \\
\hline
\end{tabular}

identification time, $t_{i}$, and its use in relations $(10,11)$ for an alternative estimation of the origin time of an ensuing mainshock and an independent test of the results obtained by the above-described method.

\section{DISCUSSION}

Attempts to calculate the origin time, $t_{c}$, of an oncoming mainshock by direct application of relation (2) do not give satisfactory results because this calculation is very sensitive to errors introduced in the parameters of this relation. For this reason, other methods have been applied for estimation of $t_{c}$. The method proposed in the present paper is also based on the critical earthquake concept and on the accelerating seismic deformation but also makes use of the precursory seismic excitation that occurs in the preshock (critical) region in excess of the accelerating activity predicted by relation (2). This additional seismic excitation can be a swarm of shocks or a normal seismic sequence consisting of a mainshock (smaller than the expected one) and its aftershocks and foreshocks. Information on swarms of shocks has also been used by other researchers for earthquake prediction purposes (Evison and Rhoades, 1997). The concept of additional seismic excitation before the mainshock may initially appear to be contradicting the model described by equation (2). However, it is known that variations due to excitations, swarms, etc. are expected with respect to the model of equation (2), and in some cases specific modeling (e.g. log-periodic, see Sornette and Sammis, 1995) can be made for these variations. In the present work we have demonstrated that the last such major excitation before the mainshock is: a) responsible for the identification of the accelerated deformation phenomenon (using the criteria of equation 3 ) and, b) occurs at a predefined time (equations 10,11 ) which can be used in the manner shown in figure (1) to identify the probable mainshock origin time.

There are, however, some important questions with respect to the method described above for the predic- 


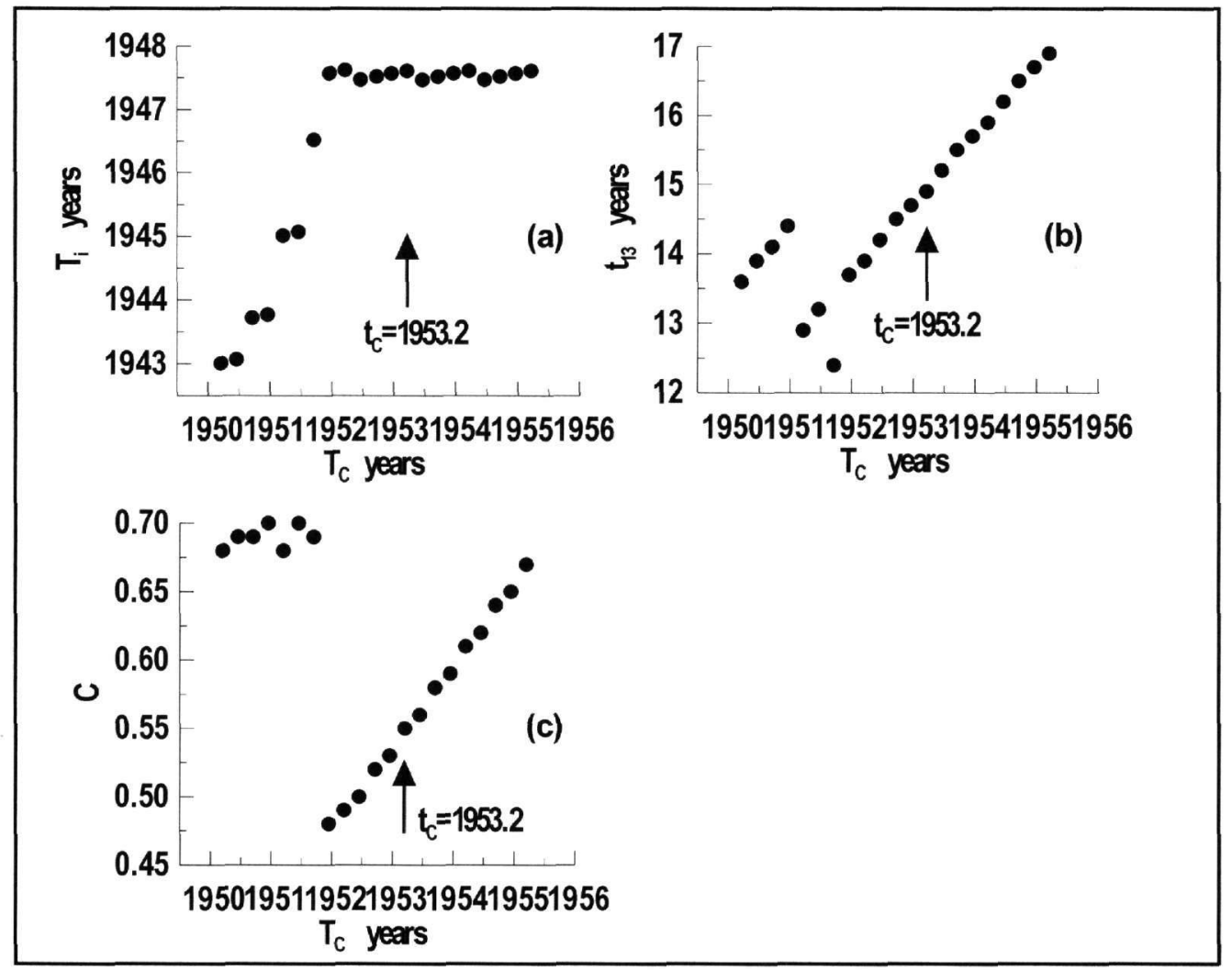

Figure (1) shows an example of a $T_{i}-T_{c}$ a $t_{13}{ }^{-} T_{c}$ and a $C-T_{c}$ graph for the $13.08 .1953, M=7.4,40.0^{0} N, 27.5^{0} E$ earthquake, where the origin time, $t$, of this shock is also indicated by an arrow. It is observed that an abrupt increase of $T_{i}$ and decrease of $t_{13}$ and $C$ occur for $T_{c}=T_{p r}=1951.71$. It corresponds to $T_{i}=1947.57$ which is the time when this precursory phenomenon (seismic excitation) took place. We should point out that C does not decrease (as expected) as we get closer to the mainshock time, $T_{c}$, because we allow $T_{c}$ to vary and take several values that are "candidates" for the "real" mainshock occurrence times, $t_{c}$.

Figure 1.- Variation: (a) of the calculated identification time, $T_{p}(b)$ of the mean difference of the three largest preshocks, $t_{13}$ and (c) of the curvature parameter, $C$, with the assumed origin time, $T_{c}$, for the mainshock of 18.03.1953 $M=7.4 . t_{c}$ is the real origin time of this earthquake. An increase of $T_{i}$ associated with a change of the slope of the $T_{i}-T_{c}$ graph and with decrease of $t_{13}$ and $C$ is observed at $T_{i}=1947.57$ when a precursory seismic excitation took place.

tion of $t_{c}$. One such question is whether this precursory excitation appears before all mainshocks or not. Another question concerns the uncertainties (errors) involved in the predicted by this method origin time of an oncoming mainshock. For this purpose the method has been applied to retrospectively predict the origin time of all very strong mainshocks $\left(\mathrm{M}^{3} 6.5\right)$ that occurred in the Aegean area since 1940 and of all strong mainshocks (6.0£M£6.4), which occurred in this area since 1970 (a total of 32 mainshocks). A period of five years was selected to be investigated for each mainshock (three years before and two years after) and the preshock excitation indicator was calculated in steps of three months.

These data showed that in 30 out of 32 cases one or more precursory seismic excitation has been observed. For each studied case the PEI has been calculated in order to identify the appropriate excitation. It was found that the calculated maximum values of PEI vary between 0.22 and 1.0 with an average equal to 0.63 and a standard deviation equal to 0.19 . That is, the precursory phenomenon appears in about $94 \%$ of the cases and the method described above ( $\mathrm{T}_{-}-\mathrm{T}_{c}$ graph, etc.) can be applied. In the other two cases such precursory excitation has not been observed and the $T_{i}-T_{c}$ graph is a straight line parallel to the $T_{i}$ axis. In these two cases $t_{c}$ has been calculated by application of relations $(10,11)$ since $t_{i}$ is equal to the constant $T_{i}$ value in this graph. 
The 12 cases with a single abrupt $T_{i}-T_{c}$ change show an almost zero bias with a standard deviation of 0.88 years. When all 30 cases are considered and if we use PEI to define the $T_{p r}$ we found a similar almost zero bias and a very slightly higher standard deviation of 0.93 . Therefore, this index can be used even in cases with multiple $T_{i}-T_{c}$ jumps and is able to identify $T_{p r}\left({ }_{c} T_{c}\right)$ with a high accuracy. If we take into account that a random distribution of this difference for the five years period examined has an equivalent standard deviation much larger ( $\sigma=1.39$ years), the obtained result ( $\sigma=0.93$ years) suggests that this estimate is statistically quite significant. We can, therefore, conclude that the origin time of an oncoming mainshock can be calculated with an uncertainty \pm 1.5 years by this method and a high confidence ( $90 \%)$.

The method described in this paper has been applied to preshock sequences already occurred for which the epicenter coordinates and magnitudes of their mainshocks were known and used in this procedure. It will be of interest to apply this method to earthquakes for which the epicenter coordinates and magnitudes have also to be predicted. Such work is already carried out. Preliminary results show that the typical error in the predicted time of an expected earthquake is of the same order, that is \pm 1 year (very close to the value of 0.93 years estimated here), while the errors in its predicted magnitude is \pm 0.4 and its predicted epicenter is less than $100 \mathrm{~km}$.

It is clear that the method proposed in the present paper identifies the critical time, that is the time that the whole phenomenon enters a critical state, which (in principle) does not necessarily coincide with the origin time of the mainshock, as the mainshock might delay to occur or may even never occur. On the other hand, in all the examined cases we have previously examined there was no case where delay in the main event occurrence was observed after entering the critical state. Therefore, the critical time identified in the present paper is identical with the origin time of the forthcoming event, provided that the event will occur.

\section{ACKNOWLEDGEMENTS}

This work has been partially supported by the Greek Planning and Protection Organization (OASP), Res.Comm.AUTH project 20242 and is Geophysical Laboratory contribution number \#564/2001.

\section{REFERENCES}

ANDERSEN, J.V., SORNETTE, D., AND LEUNG, K.T. 1997. Tri-critical behavior in rupture induced by disorder, Phys. Rev. Lett. 78, $2140-2143$.

BOWMAN, D.D., OUILLON, G., SAMMIS, C.G., SORNETTE, A. AND SORNETTE, D. 1998. An observational test of the critical earthquake concept, J. Geophys. Res. 103, 24359-24372.

BUFE, C.G., AND VARNES, D.J. 1993. Predictive modelling of seismic cycle of the Great San Francisco Bay Region, J. Geophys. Res. 98, 9871-9883.

ELLSWORTH, W.L., LINDH, A.G., PRESCOTT, W.H. AND HERD, D.G. 1981. The 1906 San Francisco earthquake and the seismic circle. In Earthquake Prediction: An International Review (eds. Simpson, D.W. and Richards, P.G.) (AGU, Washington, D.C. 1981), 126-140.

EVISON, F.F. AND RHOADES, D.A. 1997. The precursory earthquake swarm in New Zealand, Journal of Geology and Geophysics 40, 537-547.

GUTENBERG, B. AND RICHTER, C. F. 1954. Seismicity of the earth and associated phenomena, (Hafner, New York 1954).

KARAKAISIS, G. F., KOUROUZIDIS, M. C. AND PAPAZACHOS, B. C. 1991. Behavior of the seismic activity during a single seismic cycle. International Conference on Earthquake prediction: State-of-the-art, Strasbourg, France, 15-18 October 1991, 47-54.

KNOPOFF, L., LEVSHINA, T., KEILIS-BOROK, V.J. AND MATTONI, C. 1996. Increased long-range intermediate-magnitude earthquake activity prior to strong earthquakes in California, J.Geophys. Res. 101, 57795796.

MOGI, K., 1969. Some features of the recent seismic activity in and near Japan, 2, activity before and after great earthquakes, Bull. Earthquake Res. Inst., Univ. of Tokyo 47, 395-417.

PAPADOPOULOS, G.A. 1986. Long term earthquake prediction in the western Hellenic Arc, Earthquake Predic. Res. 4, 131-137.

PAPAZACHOS, B. C. AND PAPAZACHOS, C. B. 2000a. Accelerated preshock deformation of broad regions in the Aegean area, Pure appl. geophys. 157, 1663-1681.

PAPAZACHOS, C. B. AND PAPAZACHOS, B. C. 2000b. Precursory seismic deformation in the Aegean area, Annali di Geofisica (submitted).

RALEIGH,C. B., SIEH, K., SYKES, L.R. AND ANDERSON, D.L. 1982. Forecasting Southern California earth- 
quakes, Science 217, 1097-1104.

PAPAZACHOS, B.C., COMNINAKIS, P.E., KARAKAISIS, G.F., KARAKOSTAS, B.G., PAPAIOANNOU, CH.A., PAPAZACHOS, C.B. AND SCORDILIS, E.M. 2000. A catalog of earthquakes in Greece and surrounding area for the period 550BC - 1999, Publ. Geophys. Lab., Univ. of Thessaloniki, 1, 338pp.

SORNETTE, A. AND SORNETTE, D. 1990. Earthquake rupture as a critical point. Consequences for telluric precursors, Tectonophysics 179, 327-334.

SORNETTE, D., AND SAMMIS, C. G. 1995. Complex critical exponents from renormalization group theory of earthquakes: Implications for earthquake predictions, J. Phys. I. 5, 607-619.

SYKES, L.R. AND JAUME, S. 1990. Seismic activity on neighboring faults as a long term precursor to large earthquakes in the San Francisco Bay area, Nature 348, 595-599.

TOCHER, D. 1959. Seismic history of the San Francisco bay region, Calif. Div. Mines Spec. Rep. 57, 39-48.

TZANNIS, A., VALLIANATOS, F. AND MAKROPOULOS, K. 2000. Seismic and electric precursors to the 171-1983, M7 Kefallinia earthquake, Greece: signatures of a SOC system, Phys. Chem. Earth 25, 281-287. 